\title{
NOVOS ESPAÇOS DE AFETO E CUIDADO EM TEMPOS DE ISOLAMENTO SOCIAL
}

\author{
Célio Moacir dos Santos ${ }^{\mathrm{i}}$ \\ Janneyde Pascoal da Silva ${ }^{\text {ii }}$ \\ Jair Paiva ${ }^{\text {iii }}$
}

\begin{abstract}
Resumo: As circunstâncias impostas pelo isolamento social, em virtude da pandemia do novo coronavírus, acarretaram mudanças na dinâmica de um projeto denominado "Cuide-se". Anteriormente de caráter presencial, depois adequou-se para um modelo não presencial com uso de aplicativos de mensagens instantâneas e dispositivos de videochamadas. Objetivou-se com o projeto oferecer acolhimento psicológico aos estudantes. Utilizou-se dos pressupostos de Bardin (2011), da teoria do Discurso do Sujeito Coletivo (DSC) de Lefèvre e Lefèvre (2005) e das relações de grupo de acordo com Lane (2003). Constataram-se grandes impactos relacionados à saúde mental dos estudantes e como estes impactos interferem e prejudicam a rotina dos alunos.
\end{abstract}

Palavras-chave: Pandemia; Tecnologia; Categorias; Grupos; Vínculo.

\section{NEW SPACES OF AFFECTION AND CARE IN TIMES OF SOCIAL ISOLATION}

\begin{abstract}
The circumstances imposed by social isolation due to the pandemic led to changes in the dynamics of a project called "Take care". Previously face-to-face and later adapting to a non-face-to-face model using instant messaging applications and video calling devices. The aim of the project was to offer welcoming students. We used the assumptions of Bardin (2011), the theory of the Collective Subject Discourse (DSC) by Lefèvre and Lefèvre (2005) and group relations according to Lane (2003). There were major impacts related to students' mental health and how they interfere and impair their routines.
\end{abstract}

Keywords: Pandemic; Technology; Categories; Groups; Link.

\section{Introdução}

Nesse relato, é apresentado o desenvolvimento do projeto denominado "Cuide-se", uma iniciativa de cunho pedagógico e de estratégia extraclasse, em vigência há um ano, que foi inicialmente realizado em caráter presencial e, recentemente, dado o contexto atual de isolamento social ${ }^{\mathrm{iv}}$, assumiu um formato não presencial com o uso de mensagens instantâneas e aplicativos de serviço de comunicação por vídeo. 
Nessa etapa não presencial, inicialmente, foi estabelecido contato com as turmas da $3^{\text {a }}$ série do Ensino Médio de uma escola pública estadual do município de Aracruz- ES, sendo solicitado um depoimento livre sobre os dias de confinamento social. Após um tempo de coleta e escuta ativa desses estudantes, através do aplicativo de mensagem instantânea, percebeu-se a necessidade de se pensar uma ação de apoio psicológico que atendesse às demandas apresentadas e que, ao mesmo tempo, respeitassem as regras do isolamento social. Assistidos por uma psicóloga, formou-se um grupo de estudantes com idades entre 16 e 18 anos, que participaram desse momento sempre no horário de $13 \mathrm{~h} 00 \mathrm{~min}$ às $14 \mathrm{~h} 00 \mathrm{~min}$, entre os meses de março a abril.

A partir dos registros obtidos após os encontros, utilizaram-se do método de categorização de Bardin (2011). As análises dos registros ocorreram à luz da Teoria do Discurso do Sujeito Coletivo de Léfevre e Léfreve (2005) e com os estudos desenvolvidos na área de psicologia em que se trabalha com grupos de indivíduos segundo Lane (2003).

Diante do projeto alguns objetivos foram traçados, ou seja, através dessa ação buscouse oferecer acolhimento aos estudantes, minimizar os impactos que possam interferir no desenvolvimento cognitivo e atuar como suporte na permanência do aluno na instituição escolar.

Para a realização deste trabalho, tomaram-se alguns cuidados, no que tange à ética na pesquisa na área das ciências humanas, por se tratar de grupos de estudantes, observando a legislação vigente. ${ }^{\mathrm{v}}$

\section{2. Ética na pesquisa}

No cenário das discussões sobre regulação da ética em pesquisa, abrangendo os seres humanos em relação direta com possíveis impactos na pesquisa em ciências humanas e sociais, se faz oportuno tratar sobre o tema com o propósito de sustentar reflexões nessas investigações com temáticas relacionadas à educação.

Mas o que é ética? Como podemos esclarecer o seu conceito? De acordo com Hermann (2017), a ética é um campo do conhecimento de aspecto filosófico que se propõe em estudar os valores no tocante ao bem e ao mal e uma determinação estabelecida na sociedade e na cultura, que orienta o agir humano.

Outro ponto importante que deve ser considerado relacionado à ética, é o que Vieira (2010) e Orlandini (2013) discutem sobre a integridade da pesquisa. Segundo esses autores, o tema vem ganhando espaço na comunidade científica, sendo cada vez mais discutido. Desse 
modo, aspectos como a honestidade no tratamento dos dados e na divulgação do conhecimento, tanto na escrita, como na publicação dos resultados de pesquisa, são primordiais dentro dos valores éticos para a produção de conhecimento.

Com relação aos aspectos legislativos, em 1996, foi aprovada a Resolução do Conselho Nacional de Saúde (CNS) n $n^{\circ}$ 196/1996, a qual apresentava diretrizes e normas regulamentadoras de pesquisas envolvendo seres humanos. Esse documento se baseou nas principais legislações internacionais que emanaram declarações e diretrizes sobre pesquisas que envolvem seres humanos. Com relação à ética na pesquisa com seres humanos, a Resolução CNS n 196/1996 trata que se devem seguir determinações como:

a) consentimento livre e esclarecido dos indivíduos-alvo e a proteção a grupos vulneráveis e aos legalmente incapazes (autonomia). Neste sentido, a pesquisa envolvendo seres humanos deverá sempre tratá-los em sua dignidade, respeitá-los em sua autonomia e defendê-los em sua vulnerabilidade;

b) ponderação entre riscos e benefícios, tanto atuais como potenciais, individuais ou coletivos (beneficência), comprometendo-se com o máximo de benefícios e o mínimo de danos e riscos;

c) garantia de que danos previsíveis serão evitados (não maleficência);

d) relevância social da pesquisa com vantagens significativas para os sujeitos da pesquisa e minimização do ônus para os sujeitos vulneráveis, o que garante a igual consideração dos interesses envolvidos, não perdendo o sentido de sua destinação sócio-humanitária (justiça e equidade) (BRASIL, 1996).

Podemos destacar que, palavras como autonomia, beneficência, não maleficência, justiça e equidade devem fazer parte das pesquisas que envolvem seres humanos. Sobre isso, o Ministério da Saúde, em sua Resolução nº66/2012, também estabelece as diretrizes e normas que devem, obrigatoriamente, serem seguidas nesse tipo de pesquisa. Em linhas gerais, a referida Resolução indicava que toda pesquisa envolvendo seres humanos deveria ser submetida à apreciação de um Comitê de Ética em Pesquisa (CEP) e que as instituições, nas quais se realizassem pesquisas envolvendo seres humanos, deveriam constituir um ou mais de um CEP, conforme suas necessidades.

Pensando nisso, em todo o procedimento e análise da prática do projeto "Cuidese"foram observadas as devidas questões éticas no que se refere à exposição de nomes, dada a proposta que envolvia questões psicológicas; atentou-se também, para a não exibição de imagem, de modo a preservar a integridade dos alunos inseridos no projeto. Este seguiu as orientações do Ministério da Saúde conforme Resolução n ${ }^{0}$ 510, de 7 de abril de 2016 em que preconiza o diálogo, a confiança e a liberdade, como reitera o Art. 4, a saber: 
O processo de consentimento e do assentimento livre e esclarecido envolve o estabelecimento de relação de confiança entre pesquisador e participante, continuamente aberto ao diálogo e ao questionamento, podendo ser obtido ou registrado em qualquer das fases de execução da pesquisa, bem como retirado a qualquer momento, sem qualquer prejuízo ao participante(BRASIL, 2016).

Ainda de acordo com a recomendação da Resolução em relação à parte documental ao iniciar o processo terapêutico, em sua fase presencial, foi enviado um termo de consentimento aos responsáveis desses estudantes por não possuírem a maioridade legal. Foi exposto de forma clara, conforme prescreve o Art. 2:

Sua justificativa, seus objetivos, métodos, potenciais benefícios e riscos, concebido na medida da compreensão do participante, a partir de suas características individuais, sociais, econômicas e culturais, e em razão das abordagens metodológicas aplicadas (BRASIL, 2016).

Todos os procedimentos que determinaram essa pesquisa foram esclarecidos por meio de uma conversa mediada pelas psicólogas e professora conjuntamente com os participantes do projeto. Vale ressaltar ainda que, durante a realização do projeto os familiares eram comunicados semanalmente para avaliar a importância da permanência no processo, bem como, o tratamento de outras questões.

\section{O projeto: o início e novas abordagens}

A idealização do projeto nasceu em uma aula de História sobre Grécia Antiga, no $1^{\circ}$ ano do Ensino Médio em 2018. Após o estudo comparativo das duas principais cidades-estados, Atenas e Esparta, foi proposto para as turmas uma pesquisa sobre o culto ao corpo. Os povos gregos apreciavam a formosura de um corpo saudável e harmonioso. Conforme Barbosa, Matos e Costa (2011), o corpo era valorizado pela sua saúde, capacidade atlética e fertilidade. Para os gregos, em cada idade havia um estágio de beleza, o físico e o intelecto estavam relacionados com a plenitude, sendo que um corpo perfeito era tão importante quanto uma mente brilhante.

A imagem do corpo grego, ainda hoje atraente e considerada uma referência, é bastante revelador da existência e dos ideais estéticos veiculados na altura. $\mathrm{Na}$ verdade, este corpo era radicalmente idealizado, treinado, produzido em função do seu aprimoramento [...] a imagem idealizada corresponderia ao conceito de cidadão, que deveria tentar realizá-la, modelando e produzindo o 
seu corpo a partir de exercícios e meditações. O corpo era visto como elemento de glorificação e de interesse do Estado. (BARBOSA; MATOS; COSTA, p.24, 2011).

É interessante notar como, nos nossos dias, a necessidade de se encaixar em um padrão estético pode desencadear uma crise de autoimagem. Importante observar como as menções ao corpo, sejam elas científicas, tecnológica, publicitária, médica, estética, ocupam-se de forma simbólica/subjetiva do indivíduo, invadindo as dimensões expressivas e simbólicas da corporeidade, fornecendo imagens e informações que reconfiguram o próprio âmbito da vivência corporal, Novaes (2006). Ainda de acordo com esse autor, todos esses cuidados com o corpo acontecem no sentido de tentar superar o enfrentamento dos julgamentos sociais, visto que há uma imposição de valores estéticos pelos meios de comunicação que forçam a sociedade a seguir padrões como requisitos de inserção e aceitação social.

Após uma análise comparativa entre Atenas e Esparta, os alunos foram orientados a realizarem uma pesquisa sobre alguns aspectos resultantes, na atualidade, da relação com corpo humano, como, por exemplo, a bulimia, a anorexia, uso de anabolizantes e de procedimentos cirúrgicos clandestinos. O resultado da pesquisa deveria ser apresentado em forma de gráficos, slides, vídeos ou depoimentos.

A apresentação dos trabalhos ocorreu como proposto e, ainda, os alunos trouxeram depoimentos pessoais socializando-os em sala de aula. Percebeu-se, de forma clara, que momentos como esses de reflexão e escuta deveriam continuar, porém, em um espaço onde os alunos estivessem dispostos a conversarem sobre suas emoções.

Foi nesse momento que o projeto "Cuide-se" começou a ser idealizado, porém, devido a uma rotina intensa de atividades, ele só se concretiza apenas no início de 2019.

Inicialmente acreditou-se que as demandas seriam restritas a questões físicas, porém, percebeu-se que novas questões emergiam. Conforme Mendes et al. (2017), baseado na teoria de Jean William Fritz Piaget (1896-1980), o intelecto é formado por dois componentes, o afetivo e o cognitivo, portanto, o projeto se encaixa dentro da necessidade de um suporte emocional, visando a melhoria do desempenho escolar.

Ainda no final do ano de 2018 alguns contatos foram feitos e a ideia inicial apresentada para a escola, enquanto outras ações eram realizadas de maneira a trabalhar a baixa autoestima das estudantes.

A primeira ação do projeto se deu no ano de 2019 , na segunda quinzena de março. O primeiro convite foi feito a uma esteticista que desenvolveu dinâmicas com um grupo de alunas 
do turno vespertino, sempre com o intuito de promover a valorização pessoal. Durante todo processo, observamos nos (as) alunos (as) muita angústia, desânimo, falta de perspectiva pessoal e profissional, reafirmando a ideia inicial de que o projeto teria outras demandas. Outro ponto importante a ser destacado, era a agressividade por parte de algumas alunas, tornando clara a necessidade de se trabalhar a afetividade.

De acordo com Melo e Morais (2019), a maneira como se relacionam os membros de uma comunidade escolar estão intimamente ligadas ao clima escolar, e este por sua vez, no desempenho dos estudantes. Escolas que apresentam um clima desfavorável tendem a não ter bons resultados de aprendizagem e permanência durante o percurso do ano letivo. Sobre isso, concordamos com Brault e Reidy (2004) e Taylor (2008), quando ambos tratam da questão do clima escolar. Esses autores correlacionam esse fator ao desempenho acadêmico mostrando que escolas com contextos socioeconômicos desfavoráveis, porém, apresentando um bom clima escolar, conseguem obter melhor resultado na aprendizagem.

A partir do primeiro, encontro ficou ainda mais explícita a importância dessa ação e da necessidade de propiciar esses momentos de inclusão afetiva. Compartilhamos os pressupostos de Arantes (2003) ao tratar da necessidade de superação do dualismo entre cognição e afetividade, principalmente quando tratamos no âmbito escolar, do qual os afetos infelizmente tendem a ficar excluídos.

Os encontros posteriores foram realizados por três psicólogas e ocorriam em dois períodos distintos. Uma vez por mês fazíamos o convite a um grupo de alunos para participarem de uma roda de conversa, e assim permaneceu até o mês de setembro. Alguns dos casos expostos na roda de conversa demandaram outras ações, algumas que exigiam a ação da escola com a família, com órgãos como o Conselho Tutelar e outras um direcionamento para uma nova forma de intervenção. Percebendo isso, as psicólogas notaram que o intervalo de interação com os estudantes era muito longo, e que alguns necessitavam de serem integrados em um processo terapêutico. Após o convite e escolha dos alunos que participariam dessa nova ação, foi encaminhado um termo de consentimento para os responsáveis, bem como, a formação de um grupo de mensagens eletrônicas para uma melhor interação entre escola e família.

Dando prosseguimento ao ano de 2020, logo na segunda quinzena do mês de março, o projeto, tal como estava sendo proposto, necessitou ser paralisado devido à necessidade de isolamento social, imposto pela pandemia.

A questão que se colocava então era: como se criar um momento de escuta ativa e de acolhimento durante a pandemia desenvolvendo ao mesmo tempo, a ética e o respeito em relação a sua própria história de vida e a do outro? 


\section{A pandemia e seus reflexos na educação: a utilização de recursos tecnológicos.}

De acordo com Rothan e Byrareddy (2020), a Covid-19 é uma síndrome respiratória aguda grave causada pelo SARS-COV-2 e representa o agente causador de uma doença potencialmente fatal que é um grande problema de saúde pública global. Devido a essa situação, na segunda quinzena do mês de março de 2020, com as políticas de isolamento social de combate ao contágio, o Brasil teve que mudar de forma drástica o cotidiano da população, com alterações nos mais diferentes campos, seja economicamente, social e ambientalmente. Filho et al. (2020) colaboram dizendo que esses procedimentos ocasionaram um encadeamento de demandas, a saber:

A identificação de uma série de processos já em largo estágio de avanço nos mais diversos setores, da pauta macroeconômica à social ou ambiental, que por sua vez, se desdobram em uma série de pontos tão diversificados que é quase impossível sintetizá-los em um quadro amplo de análise (FILHO et al., p.17, 2020).

Alguns aspectos são colocados como um alerta para inserção de estudantes no projeto, como, por exemplo, mudança no rendimento escolar, isolamento, desinteresse em participar de atividades, dentre outros. A forma de visualização desses aspectos durante a pandemia do Covid-19 se deu através dos depoimentos colhidos dos estudantes que relataram como estavam vivendo esses dias de isolamento social. Suas angústias, medos e insatisfações foram ouvidos e o projeto assume uma nova versão: o atendimento via mensagens eletrônicas e aplicativos de videochamadas.

Sobre a interação dos indivíduos nas redes sociais, Lapa e Girardello (2017) colaboram afirmando que através do ciberespaço as pessoas podem formar comunidades tão intensas quanto as presenciais através da criação de laços interpessoais que proporcionam integração e a construção de uma identidade social.

Embora ainda não seja possível avaliar todas as consequências ocasionadas pela pandemia, já se pode senti-las de forma candente na sociedade, exigindo dos governos de várias esferas as mais variadas ações na tentativa de amenizar esses problemas no cenário brasileiro.

Diante de toda essa problemática, podemos destacar o sistema educacional, uma vez que, em função dessa pandemia, muitos estudantes perderam o direito básico à educação em 
seus mais diferentes níveis de ensino, colocando em questão o que preconiza a Constituição Federal em seu Art. 205, a saber:

A educação, direito de todos e dever do Estado e da família, será promovida e incentivada com a colaboração da sociedade, visando ao pleno desenvolvimento da pessoa, seu preparo para o exercício da cidadania e sua qualificação para o trabalho. (BRASIL, 1988).

Nesta perspectiva, diante do atual cenário, o sistema educativo busca novas possibilidades para se reinventar em vistas a presente realidade, uma vez que, ainda, não é possível definir quando essa crise será estabilizada. No Parecer do Conselho Nacional de Educação (CNE), de 28 de abril de 2020, são propostas a reorganização dos calendários escolares e realização de atividades pedagógicas não presenciais durante o período de pandemia da COVID-19. Esse decreto foi elaborado a partir de consultas públicas formuladas ao CNE.

No entanto, o Parecer deixa aspectos relevantes, como a redefinição de calendário escolar, para serem apreciados pelos entes federativos e sistemas de ensino, bem como ressalta que pode haver pareceres específicos de órgãos internos do CNE (Câmara de Educação Básica e Câmara de Ensino Superior).

O que não se pode negar é que a pandemia do novo coronavírus exigiu que todas as áreas da sociedade viabilizassem alternativas para tentar superar os impactos negativos que ela tem ocasionado. No caso específico do sistema educacional, a educação a distância (EaD), por intermédio da tecnologia e suas inúmeras ferramentas, tem sido considerada uma alternativa para amenizar tais impactos, em função do distanciamento social que em via de regra, tem sido utilizado como a principal medida de combate ao vírus.

Sobre a EaD, o Art. $1^{\circ}$ do Decreto ${ }^{\circ} 9.057$ (2017) enfatiza que:

Art. $1^{\circ}[\ldots]$ considera-se educação a distância a modalidade educacional na qual a mediação didático-pedagógica nos processos de ensino e aprendizagem ocorra com a utilização de meios e tecnologias de informação e comunicação, com pessoal qualificado, com políticas de acesso, com acompanhamento e avaliação compatíveis, entre outros, e desenvolva atividades educativas por estudantes e profissionais da educação que estejam em lugares e tempos diversos. (BRASIL, 2017).

Entendemos que com relação aos recursos utilizados no ensino a distância, a modalidade $\mathrm{EaD}$ inspirou o ensino remoto e novas práticas no sistema educacional, visto que o mesmo 
precisou ser modificado em um curto espaço de tempo devido à necessidade de isolamento social.

Atualmente, existem diversas tecnologias sendo utilizadas no ensino remoto, sendo que essas inovações ocorrem sempre de maneira integrada. De acordo com Oliveira e Santos (2020), os materiais impressos, os recursos audiovisuais e os ambientes virtuais têm beneficiado as pessoas, oportunizando para que haja uma flexibilidade de encontros presenciais.

No entanto, em conformidade com Oliveira e Souza (2020), apesar dessa possibilidade, inúmeras questões precisam ser analisadas para que essa alternativa seja legítima a todos os estudantes. Porém, não é objetivo deste trabalho entrar no mérito desta questão. Apoiamo-nos em Lévy (1999), que ressalta a importância do uso das tecnologias utilizadas como recursos didáticos, redefinindo a função docente e agregando às práticas de ensino e aprendizagem novos modos de acesso aos conhecimentos.

O aperfeiçoamento de recursos tecnológicos, utilizados como ferramentas pedagógicas, tem se mostrado rápido e, ao mesmo tempo, extremamente dinâmico. Mensagens eletrônicas instantâneas enviadas por dispositivos móveis e aplicativos de videochamadas, por exemplo, ganham diferentes usos em processos de ensino e aprendizagem.

Em se tratando, mais especificamente, das mensagens instantâneas, estas se constituem em um dos melhores canais de comunicação, dada a sua facilidade de manuseio e ao acesso a esse dispositivo, visto que necessita apenas ter a conexão com a internet.

Sobre isso, afirmam Teles e Silva (2016) que essas formas de comunicação são um dos meios em que,

[...] a aprendizagem colaborativa acontece, entretanto, entende-se que, para além de uma aprendizagem restrita aos conteúdos tradicionais do currículo escolar, podem avançar para a compreensão de uma possibilidade de formação ampla e participação social e política (TELES; SILVA; 2016, p. 2).

Consideramos o grande potencial das mensagens instantâneas e dos aplicativos de videochamadas para a continuidade do projeto "Cuide-se". A partir dessa constatação acerca desse recurso, percebe-se outro grande atributo: a possibilidade de manutenção do vínculo professor e aluno mediante a necessidade do isolamento social em virtude da pandemia. Obviamente, entendemos que o contato físico não pode ser comparado a uma experiência virtual, pois a troca presencial traz sentimentos e percepções diferentes das vivenciadas on-line.

\section{Procedimento Metodológico}


Em um primeiro momento, é abordada a importância do processo de classificação de categorias em investigações que têm por natureza tratar de grupos de indivíduos. "A maioria dos procedimentos de análise organiza-se, no entanto, ao redor de um processo de categorização" Bardin (2011, p.147). Segundo a autora, a função principal da análise do conteúdo é apuração crítica. Os estudos sobre análise do conteúdo visam superar as incertezas na tentativa de enriquecer as leituras. Como fundamentação teórica, tratou-se das mensagens dos estudantes a luz da teoria do Discurso do Sujeito Coletivo - DSC de Lefèvre e Lefèvre (2005), que é um procedimento de construção do pensamento coletivo que visa evidenciar como as pessoas pensam, seus posicionamentos sobre determinada questão. Trata-se de um compartilhamento de ideias dentro de um grupo social. Também, por se tratar de um grupo, Lane (2003) retrata o potencial criativo que pode ser desenvolvido, suscitando convivência com a diferença dentro de um coletivo.

Segundo Barros (2007), o grupo ajuda os integrantes a exercitar seu potencial autogestionário. Nas palavras da autora temos:

Os primeiros recebem sua lei do exterior, são caracterizados pela hierarquia, pela organização vertical ou piramidal, [...] preservam mecanismos de autoconservação, operando por totalizações e por unificação. Já os grupos sujeitos propõem-se a pensar suas posições, abrindo-se à alteridade e aos processos criativos, conjuram as totalizações e unificações, permitem que sua prática os leve ao confronto com seus limites, sua finitude, nem buscam garantias transcendentais e se definem pelo aumento de seus coeficientes de transversalidade (BARROS, 2007, p.256).

Internamente a esse vetor, temos níveis de resistência entre os grupos, uns com capacidades de crescimento através da mudança (sujeitos) e outros submetidos às normatizações com dificuldades de aderir ao novo (sujeitados).

A linha de continuidade dessas relações entre sujeito e sujeitado, apoiado em Lane e Freitas (1998), deve manifestar-se em sua pluralidade. Em decorrência de um certo desequilíbrio entre essas relações, as mesmas merecem ser analisadas dentro de uma concepção filosófica quando observadas do ponto de vista da subjetividade. Ainda segundo esses autores, estamos diante de um enfrentamento desigual, em que de um só lado temos todas as forças, todo o poder e todos os direitos. Em contrapartida, do outro lado, vulnerável, o sujeito que transferiu todo o seu poder e que deve enfrentar sozinho com o que lhe restou, a unicidade social.

Lane (2003) nos diz que a análise de grupo se faz pertinente, uma vez que estamos inseridos em sociedade com a qual produzimos saberes, valores, regras, cultura, de tal forma 
que analisar o sujeito de forma individualizada não será possível, já que somos parte de um organismo complexo. Somos seres sociais e estamos ligados ao grupo no qual pertencemos. Sobre isso, Ávila (2003) afirma que um sujeito não se constitui sozinho, pois ele é fruto de convivências com outros, ou seja, é múltiplo.

McDougall (2016) aponta uma condição para que certa multidão se forme no sentido psicológico: os indivíduos devem ter algo em comum, devem ter o mesmo interesse. Os grupos formados, tanto nos encontros presenciais, como os não presenciais, se encaixam dentro de padrões de interesses semelhantes: sejam eles a dor do abandono, da baixa autoestima, dos abusos físicos, psicológicos e sexuais, bem como toda demanda surgida com o isolamento social, que vai de encontro com todos os itens citados, além do agravante aumento das consequências negativas do alcoolismo, a ansiedade, o sentimento de incapacidade, dada as várias mudanças ocorridas no sistema educacional, dentre outras.

Ainda sobre grupos, de acordo com Lane (2003), procurou-se compreender o processo que ocorre quando as pessoas estabelecem uma interdependência. Marrow (1977) colabora dizendo que essa interdependência pode ser em relação a uma atividade proposta ou através dos próprios membros em situações referentes à atração, afeição, etc. Assim se estabelece a ideia de sócio-grupo que é mais pragmático, um grupo de tarefa e psico-grupo onde as afinidades se manifestam.

Apoiado em Fernandes (2008), o discurso produzido pelos grupos conecta-se com a produção do sentido. E esta, produzida conforme os lugares e as situações que os sujeitos em interlocução ocupam passam a ser vistos, segundo Gondim e Fischer (2009) como expressão de um pensamento coletivo.

A partir das falas dos sujeitos no grupo, faremos a categorização de acordo com Bardin (2011) para uma melhor organização, utilizando fragmentos de algumas falas dos estudantes.

\section{Algumas constatações}

Durante os encontros presenciais, foram efetuados registros, em que os alunos eram convidados a escreverem sobre a importância desse projeto para a escola e para eles mesmos. Como a metodologia está embasada em Bardin (2011), tratando da categorização para análise de conteúdo, foi realizada a leitura dos registros e neles selecionados três categorias (quadro 1).

Quadro 1: Transcrição das categorias em momentos presenciais

\begin{tabular}{|c|c|}
\hline CATEGORIAS & TRANSCRIÇÕES \\
\hline
\end{tabular}




\section{Gratidão}

Empatia
Aluna A: "[...] me ajudou a desabafar e compartilhar coisas que jamais contei para ninguém [...]"

Aluna $C$ : "[..] gostei muito do dia, o convite veio na hora certa $[.$.$] "$

Aluna D: “[...] foi uma experiência maravilhosa, saí daquela sala renovada, com uma sensação de alívio, de poder compartilhar minha dor [...]

Aluna E: "[...] foi muito importante para mim, eu estava precisando muito desabafar $[\ldots]$ "

Aluna F: "[...] eu gostei muito de participar [...] me ajudou bastante, até mudou um pouco meu ponto de vista $[\ldots]$ agradeço pela oportunidade $[. .$.$] "$

Aluna $G$ : "[...] foi muito importante para mim, pois me senti mais leve $[\ldots]$ "

Aluna I: “[...] me ajudou muito a entender sobre depressão, [...] existem muitas pessoas que eu posso ajudar $[\ldots] "$

Aluna $K$ : “[...] valeu muito a pena, pois me ajudou muito a estar superando tudo o que eu passei [...]"

Aluna L: "“...] eu acho muito importante porque muitas alunas passam por problemas e não têm com quem conversar $[\ldots]$ ".

Aluna B: "[...] achei muito tocante o depoimento de todas as meninas $[\ldots]$ ".

Aluna $C$ : "[...]se colocar no lugar das pessoas, saber que todos nós passamos por problemas, e às vezes precisamos de ajuda para resolver, que nós alunos podemos ajudar uns aos outros por meio de palavras $[\ldots]^{\prime \prime}$

Aluna B: “[...] me dói muito lembrar de algumas situações que vivi $[\ldots]$ "

Aluna $F:$ "[...] me senti mais leve depois dessa conversa em grupo [...]"

Aluna $H:$ " [...] nem tudo a morte é a solução [...]"

Aluno $J$ : “[...] consegui exteriorizar um pouco dos meus sentimentos, que até então eu guardava só para $\operatorname{mim}[\ldots] "$

Aluna H: "[...] eu tenho muito medo [...]"

Aluna L: “[...] eu tenho muito ódio do meu avô, eu quero que ele morra, $[. .$.$] ele me fez coisas horríveis$ $[\ldots]^{\prime \prime}$

Fonte: Elaborado pelos autores

Posteriormente,nas mensagens retratadas via grupos de mensagens instantâneas e videochamadas também foram elaboradas as categorias e seus respectivos registros (quadro 2).

Quadro 2: Transcrição das categorias em momentos não presenciais
TRANSCRIÇÕES 


\begin{tabular}{|c|c|}
\hline Emoção & 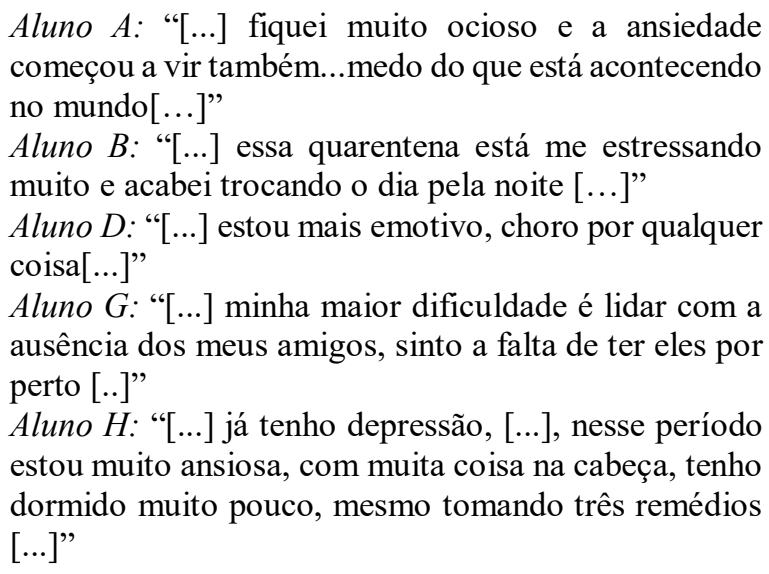 \\
\hline Autopercepção & 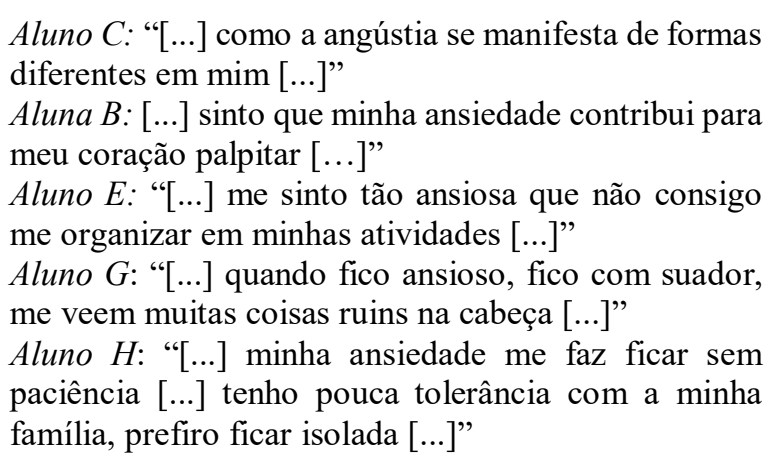 \\
\hline Luto & 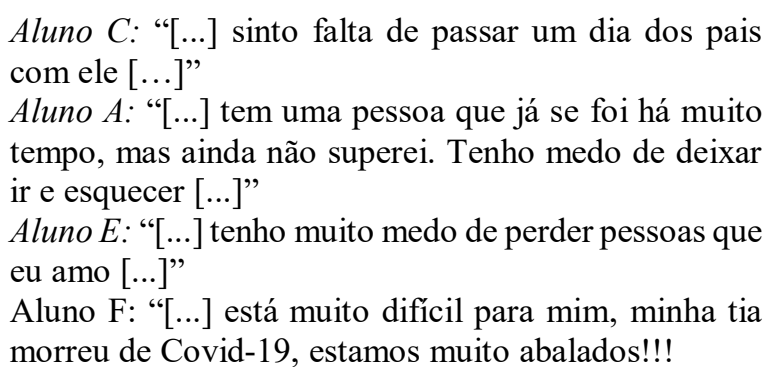 \\
\hline
\end{tabular}

Fonte: Elaborado pelos autores

Nas análises feitas, observando as categorias do quadro 1, percebeu-se que esses encontros proporcionaram momentos de empatia em que os participantes se comoviam com a dor do outro e se sensibilizavam relembrando situações vivenciadas, sentindo-se muito gratos por ter/fazer parte daquele grupo. Nas categorias do quadro 2 encontramos também, manifestações dos seus sentimentos, mas agora, com uma intensidade maior. Perceberam-se sintomas moderados a severos de ansiedade, depressão e estresse, causados pelo isolamento social em virtude da pandemia. Outro aspecto evidenciado, é a categoria luto, que compareceu nesse último quadro. Ela está intimamente ligada ao medo de se perder alguém próximo, requerendo dos estudantes equilíbrio emocional para saber lidar com essas situações.

Entendemos que, de acordo com a análise de grupo dos autores Lane (2003) e Lefèvre e Lefèvre (2005), algumas relações são percebidas nas mensagens instantâneas servindo como 
aporte para a valorização da construção do sentido compartilhado, uma vez que a proposta desses momentos tem como finalidade a escuta.

\section{Considerações finais}

Este trabalho, nascido de uma atividade didática cotidiana, se desdobrou num projeto de pesquisa com estudantes, tornando-os, de certa forma, sujeitos de sua própria educação e reflexão, nos levou a um percurso em que nos propusemos a um processo de escuta ativa e acolhimento diante da complexidade de vida que aflorou diante de nós.

Todos esses impactos na saúde mental dos estudantes interferem diretamente nas suas rotinas. A forma como lidam com seus sentimentos têm uma relação direta com a dificuldade em dar prosseguimento a seus estudos nesse período de isolamento social.

Se conseguimos atingir os objetivos propostos, em parte nos damos por satisfeitos; dizemos em parte, porque sabemos que são maiores os desafios, visto que ainda se alonga no horizonte a necessidade de isolamento social em virtude da pandemia do novo coronavírus.

Dessa forma, se a pandemia, por um lado, pôs em suspenso o tempo de aprendizagem da escola, ao mesmo tempo nos impôs a necessidade de responder, ainda que de forma remota e imersos em nossas próprias vidas familiares, aos desafios representados pela vida dos jovens que vínhamos acompanhando.

Pensando em uma possível continuidade do projeto, realizou-se uma pesquisa com os participantes através de um formulário virtual. Como resultados tivemos cerca de $95 \%$ de satisfação dos estudantes para com o projeto, bem como, se posicionando pela sua continuidade.

Ao ler os relatos, nos sentimos felizes porque suas falas mostram que os objetivos foram atingidos: reatar laços com subjetividades frágeis, proporcionando um tempo e um espaço de ouvir angústias, ansiedades e desencontros na vida de estudantes, num tempo também marcado por fraturas, crises e inseguranças quanto ao amanhã.

A suspensão do tempo dos jovens na escola e o consequente isolamento social ainda serão estudados em todas as suas magnitudes. Aquelas mais visíveis já estão na mídia sob todas suas formas: desemprego, migração para comércio eletrônico, fechamento de empresas, reinvenção; também, não se pode negar, de outras, com redefinição de espaços e tempos de aprender, conviver, dar sentido às suas vidas, ainda numa indefinição quanto ao retorno às atividades presenciais. 
Mesmo diante de muitas dificuldades, o projeto "Cuide-se", em seus diferentes formatos, procurou cumprir seus objetivos, e contribuiu para uma melhor compreensão do momento delicado vivenciado pelos estudantes participantes dessa ação. Nossa contribuição, ainda que modesta, representa uma tentativa da escola se fazer presente na vida dos jovens.

\section{Referências}

ARANTES, V. A. Afectividade na escola: alternativas teóricas e práticas. Grupo Editorial Summus, 2003.

AVILA, R. Resultados da reabilitação neuropsicológica em pacientes com doenças de Alzheimer leve. Revista de Psiquiatria Clínica, 2003.Disponível em: $<$ https://www.scielo.br/scielo.php?pid=S0101-60832003000400004\&script=sci_arttext>. Acesso em 20 abr. 2020.

BARBOSA, M. R.; MATOS, P. M.; COSTA, M. E. Um olhar sobre o corpo: o corpo ontem e hoje. Psicologia \& Sociedade, v. 23, n. 1, p. 24-34, 2011. Disponível em:

$<$ https://www.scielo.br/pdf/psoc/v23n1/a04v23n1>. Acesso em 04 abr. 2020.

BARDIN, L. Análise de conteúdo. Lisboa: Edições 70, 2011.

BARROS, R. B. de. Grupo: a afirmação de um simulacro. Porto Alegre: Editora Sulina/UFRGS, 2007.

BRASIL, (1988). Constituição da República Federativa do Brasil. Diário Oficial. Disponível em:<https://www2.senado.leg.br/bdsf/bitstream/handle/id/518231/CF88_Livro_EC91_2016.p df $>$. Acesso em 10 maio 2020.

BRASIL. Ministério da Educação. Portaria no 343, de 17 de março de 2020. Dispõe sobre a substituição das aulas presenciais por aulas em meios digitais enquanto durar a situação de pandemia do Novo Coronavírus - COVID - 19. Brasília, DF: MEC, 2020. Disponível em: <http://www.in.gov.br/en/web/dou/-/portaria -n-343 -de - 17 - de - março-de- 2020$248564376>$. Acesso em: 25 mar. 2020.

BRASIL. Ministério da Saúde. Conselho Nacional de Saúde. Resolução No 510, de 7 de abril de 2016. Dispõe sobre as normas aplicáveis a pesquisas em Ciências Humanas e Sociais. Diário Oficial da União: seção 1, Brasília, DF, n. 98, seção 1, p. 44-46, 24 maio 2016. Disponível em: $<$ http://conselho.saude.gov.br/resolucoes/2016/Reso510.pdf > . Acesso em 28 mar. 2020.

BRASIL. Ministério da Saúde. Conselho Nacional de Saúde. Resolução no 466, de 12 de dezembro de 2012. Aprova as diretrizes e normas regulamentadoras de pesquisas envolvendo seres humanos. Diário Oficial da União: seção 1, Brasília, DF, n. 112, p. 59-62, 13 jun. 2013. Disponível em: $<$ http://conselho.saude.gov.br/resolucoes/2012/Reso466.pdf $>$. Acesso em 5 maio 2020.

BRASIL. Ministério da Saúde. Conselho Nacional de Saúde. Resolução Nº 196, de 10 de outubro de 1996. Diretrizes e normas regulamentadoras de pesquisa envolvendo seres humanos. Diário Oficial da União: seção 1, Brasília, DF, n. 201, p. 21082-21085, 16 out. 
1996. Disponível em:

$<$ http://bvsms.saude.gov.br/bvs/saudelegis/cns/1996/res0196_10_10_1996.html >. Acesso em 25 mar. 2020.

BRASIL. Decreto $n^{0}$ 9.057, de 25 de maio de 2017. Regulamenta o art. 80 da lei $\mathrm{n}^{\circ} 9394$ de 20 de dezembro de 1996, que estabelece as diretrizes e bases da educação nacional. Disponível em<http://www.planalto.gov.br/ccivil 03/ ato2015-2018/2017/decreto/D9057.htm >.Acesso em 05 mar. 2020.

BRAULT, R.; REIDY, J. Travel education: Demonstrating effective learning through the seven principles of good practice in undergraduate education. Schole: A Journal of Leisure Studies and Recreation Education, v. 19, n. 1, p. 11-26, 2004. Disponível em: $<$ https://www.tandfonline.com/doi/abs/10.1080/1937156X.2004.11949523>. Acesso em 12 maio 2020.

FERNANDES, C. A. Representações da escola para o sem-terra. Linguagem: Estudos e Pesquisas, v. 12, n. 1, 2008. Disponível em:

$<$ https://www.revistas.ufg.br/lep/article/view/34446>. Acesso em 15 abr. 2020.

FILHO, A. L. F. et al. Alguns apontamentos para uma crítica da ead na educação brasileira em tempos de pandemia. Revista Tamoios, v. 16, n. 1, 2020. Disponível: $<$ https://www.epublicacoes.uerj.br/index.php/tamoios/article/view/50535>. Acesso em 29 abr. 2020.

GODIM, S., \& FISCHER, T. O discurso, a análise do discurso e a metodologia do discurso do sujeito coletivo na gestão intercultural, Cadernos Gestão Social, 2(1), 9-26. 2009.

Disponível em: <https://portalseer.ufba.br/index.php/cgs/article/view/31544>. Acesso em 13 abr. 2020.

HERMANN, N. Ética \& educação: outra sensibilidade. Autêntica, 2017.

LANE, S.T.M. Emoções e pensamento: uma dicotomia a ser superada. A perspectiva sóciohistórica na formação em psicologia. Petrópolis: Editora Vozes, p. 100-112, 2003.

LANE, S. T. M., \& FREITAS, S. T. M. (1998). Processo Grupal na Perspectiva de Ignácio Martin Baró: reflexão acerca de seis contextos concretos. Revista Interamericana de Psicologia, 31(2), 293-308. Disponível em:

$<$ https://dialnet.unirioja.es/servlet/articulo?codigo=3852748>. Acesso em 20 abr. 2020.

LAPA, A.; GIRARDELLO, G. Gestão em Rede na Primavera Secundarista. In. PORTO, C.; OLIVEIRA, K. E.; CHAGAS, A. (Org.). WhatsApp e Educação: entre mensagens, imagens e sons. Salvador: EDUFBA, 2017.

LEFÈVRE, F.; LEFÈVRE, A. M. C. O discurso do sujeito coletivo: um novo enfoque em pesquisa qualitativa (desdobramentos). 2. ed. Caxias do Sul: Educs, 2005.

LÉVY, P. Cibercultura. São Paulo: Editora 34, p. 260, 1999.

LIMA, S. G. et al. Ética em pesquisas com seres humanos: do conhecimento à prática.

Arquivos Brasileiros de Cardiologia, v. 95, n. 3, p. 289-294, 2010. Disponível

em: $<$ https://www.scielo.br/scielo.php?pid=S0066-782X2010001300003\&script=sci_arttext $>$. Acessoem 23 maio 2020. 
MARROW, A. J. The practical theorist: The life and work of Kurt Lewin. Teachers College Press, 1977.

MCDOUGALL, W. Modern materialism and emergent evolution. Routledge, 2016.

MELO, S. G.; MORAIS, A. Clima escolar como factorprotectordelrendimientoen condiciones socioeconómicas desfavorables. Cadernos de Pesquisa, v. 49, n. 172, p. 10-34, 2019.

Disponível em: $<$ https://www.scielo.br/scielo.php?pid=S0100-

15742019000200010\&script=sci_abstract\&tlng=es $>$. Acesso em 05 abr. 2020.

MENDES, D. et al. A influência da Autoestima no desempenho escolar. Revista de educação e debate. 2017. V.39, n. 73. Disponível em: <http://repositorio.ufc.br/handle/riufc/28211>. Acesso em 7 maio 2020.

NOVAES, J. V. Ser mulher, ser feia, ser excluída. [versão online] 2006. Disponível em: $<\mathrm{http}: / /$ www.psicologia.com.pt/artigos/textos/A0237.pdf>. Acesso em 11 fev. 2020.

OLIVEIRA, F. A.; SANTOS, A. M. S. Construção do Conhecimento na Modalidade de Educação a Distância: Descortinando as Potencialidades da EaD no Brasil. EaD em Foco, v. 10, n. 1, p. 26-26, 2020.Disponível em:

$<$ https://eademfoco.cecierj.edu.br/index.php/Revista/article/view/799>. Acesso em 25 mar. 2020 .

OLIVEIRA, H. V.; SOUZA, F. S. Do conteúdo programático ao sistema de avaliação: reflexões educacionais em tempos de pandemia (COVID-19). Boletim de Conjuntura (BOCA), v. 2, n. 5, p. 15-24, 2020. Disponível em: $<$ https://revista.ufrr.br/boca/article/view/OliveiraSouza>. Acesso em 15 maio 2020.

ORLANDINI, R. Fraudes e enganos na história da ciência. ComCiência - Revista Eletrônica de Jornalismo Científico, Campinas, n. 147, 10 abr. 2013. Disponível em:

$<\mathrm{http}: / /$ comciencia.scielo.br/scielo.php?script=sci_arttext\&pid=S1519$76542013000300003 \& \operatorname{lng}=\mathrm{en} \& n \mathrm{~nm}=\mathrm{iso} \& \operatorname{lng}=\mathrm{en}>$. Acessoem 19 maio 2020.

ROTHAN, H. A.; BYRAREDDY, S. N. The epidemiology and pathogenesis of coronavirus disease (COVID-19) outbreak. Journal of autoimmunity, p. 102433, 2020. Disponível em: $<$ https://www.sciencedirect.com/science/article/pii/S0896841120300469>. Acesso em 5 abr. 2020.

TAYLOR, D. E. The influence of climate on student achievement in elementary schools. 2008. 113 f. Dissertation (Doctor of Education) - The Faculty of the Graduate School of Education and Human Development of The George Washington University, Washington, 2008. Disponível em:

$<$ https://search.proquest.com/openview/678d7d62c93a12477caba7392d941321/1?pqorigsite $=$ gscholar\&cbl $=18750 \&$ diss $=y>$. Acesso em 23 abr. 2020.

TELES, L. F.; SILVA, L. R. A colaboração online como agente de emancipação em redes sociais. ARTEFACTUM-Revista de estudos em Linguagens e Tecnologia, v. 13, n. 2, 2016. Disponível em:

$<$ http://www.artefactum.rafrom.com.br/index.php/artefactum/article/view/1200>. Acesso em 4 maio 2020. 
VIEIRA, F. Desencontros e descaminhos de uma pesquisa sociológica em um hospital público. In: FLEISCHER, S.; SCHUCH, P. (Orgs.). Ética e regulamentação na pesquisa antropológica. Brasília: Letras Livres e Editora da UnB, 2010. p. 127-140.

${ }^{i}$ Professor da Secretaria de Estado da Educação do Espírito Santo (SEDU). Mestre em Ensino de Ciência e Matemática pela Pontifícia Universidade Católica de Minas Gerais (PUC-MINAS). Vitório. Brasil. E-mail: moacircelio@gmail.com ORCID: https://orcid.org/0000-0002-4765-1578

ii"Professora da Secretaria de Estado da Educação do Espírito Santo (SEDU).Especialização em Implementação e Gestão de Educação a Distância pela Universidade Federal Fluminense (UFF). Vitória. Brasil. E-mail: janneyde.psilva1@educador.edu.es.gov.br.ORCID: https://orcid.org/0000-0002-1665-125X

iii Professor do Departamento de Educação da Universidade Federal do Espírito Santo (UFES). Doutor em Educação pela Universidade Federal do Espírito Santo (UFES). Vitório. Brasil. E-mail: jmipaiva@gmail.com ORCID: https://orcid.org/0000-0002-6986-3213

${ }^{i v} \mathrm{O}$ termo isolamento refere-se ao ato de distanciar indivíduos. É um procedimento recomendado pelo Ministério da Saúde, esse distanciamento tem como intuito interromper a transmissão do novo coronavírus

${ }^{\vee}$ Conselho Nacional de Saúde. Resolução no 196, de 10 de outubro de 1996; Ministério da Saúde. Conselho Nacional de Saúde. Resolução n ${ }^{\circ}$ 466, de 12 de dezembro de 2012; Ministério da Saúde. Conselho Nacional de Saúde. Resolução $\mathrm{n}^{\circ}$ 510, de 7 de abril de 2016. 